\title{
Nasilje - poskus opredelitve in upravičenja
}

\author{
Ingrid Kodelja
}

$\mathrm{N}$

asilje je navzoče povsod, na nacionalni in internacionalni ravni, je del javne in privatne sfere, pojavlja se v različnih oblikah, zato ni presenetljivo, da je tudi opredeljeno na različne načine. Skozi vsa zgodovinska obdobja se je človeštvo soočalo z nasiljem. Poglejmo samo vsem znane Božje zapovedi v Drugi Mojzesovi knjigi - celotna druga polovica Dekaloga govori o prepovedi nasilja. Šesta, sedma, osma, deveta in deseta Božja zapoved prepovedujejo najhujše oblike nasilja, in sicer po vrstnem redu od hujših do milejših: »Ne ubijaj!; Ne prešuštvuj!; Ne kradi!; Ne pričaj po krivem proti svojemu bližnjemu!; Ne želi hiše svojega bližnjega! Ne želi žene svojega bližnjega ne njegovega hlapca in dekle, ne česar koli, kar pripada tvojemu bližnjemu! « (2 Mz 20, 13-17). ${ }^{1}$ Homerjeva Iliada se kaže kot ep o nasilju: celotna pesnitev je stkana iz zelo podrobnih opisov tega, kako je nasilne smrti umrl ta ali oni junak. ${ }^{2}$ Tudi 2r. stoletje se je začelo z nasiljem, z grozo dogodkov ir. septembra 200 I v New Yorku, s terorizmom in kontinuiranimi napadi na demokratične in nedemokratične države. Morda je treba prav zaradi tega, ker smo priče tem dogodkom, različne oblike nasilja natančneje opredeliti, če ga sploh hočemo omejiti ali vsaj kontrolirati. Nasilje je namreč zelo nejasen pojem, ki se ga razume in razlaga na različne načine. Na ravni izkušnje se sicer zdi, da vsi »vemo«,kaj je nasilje, ko pa skušamo navesti osnovne značilnosti, po katerih bi ga objektivizirali, se znajdemo pred težko nalogo. Pomen in raba pojma nasilja se skozi čas spreminjata. Dojemanje tega, kaj je nasilno,

I Zadnja, deseta zapoved ne prepoveduje dejanja nasilja, prepoveduje željo. O tem glej več v: Girard, 2006: 19-31.

2 Gl. Komel, 2012: 11-16. 
$\mathrm{v}$ današnjem času vključuje dejanja, ki bi jih še nedavno razumeli kot popolnoma neproblematična: takšna so denimo nasilna dejanja ljudi do živali. Poleg tega se je raba termina nasilje s kazenskega in vojaškega področja razširila tudi na druge ravni življenja in odnosov: na primer z razvojem kategorij družinskega in na spolu utemeljenega nasilja. Premišljanje o nasilju tako obsega več tipov nasilja, o katerem se v današnjem času govori: privatno in javno, subjektivno in objektivno, individualno in kolektivno, medvrstniško, direktno, medosebno in strukturno, uradno in neuradno, institucionalno, vidno in nevidno, fizično, psihično, ekonomsko in socialno nasilje, nasilje v vojni in nasilje $\mathrm{v}$ miru, policijsko nasilje, genocidno nasilje, spolno nasilje, samonasilje, diskriminacija, terorizem, kršitve pravic, neenakost. ${ }^{3}$

Nesporno dejstvo je, da je nasilje prisotno tudi v vzgojno-izobraževalnih zavodih. O njem poročajo mediji, učitelji, starši, učenci. Na Zavodu RS za šolstvo so celo pripravili Navodila spriročnikom za obravnavo medvrstniškega nasilja $v$ vzgojno-izobraževalnih zavodih $\mathrm{z}$ namenom, da zaposlenim $\mathrm{v}$ teh institucijah pomagajo bolje razumeti pojav nasilja med vrstniki ter se ustrezno odzvati, ko se tovrstno nasilje pojavi. ${ }^{4}$ Kakor za druge vrste nasilja, tudi za nasilje $\mathrm{v}$ vzgojno-izobraževalnih zavodih velja, da je odraz družbenih in/ali osebnih razmer in da se pojmovanje, kaj je nasilno, skozi čas spreminja. Pred petdesetimi leti so bili klofuta v šoli, klečanje v kotu, oslovska klop... nekaj povsem vsakdanjega, danes bi ta dejanja označili kot nasilna. Prav tako je včasih težko postaviti mejo med nasiljem, igrivostjo in razposajenostjo. Skratka, tudi pri opredeljevanju nasilja v vzgojno-izobraževalnih zavodih smo soočeni s podobnimi problemi kot pri opredelitvi drugih tipov nasilja. Tudi tu se zastavlja osnovno vprašanje: Kaj je nasilje.

V prispevku sem bom zato najprej osredotočila na to temeljno vprašanje: Kaj je nasilje. Odgovor na to pojmovno vprašanje je namreč predpogoj za vse nadaljnje razprave o nasilju: moralna upravičenost nasilja, ničelna toleranca do nasilja, terorizem, odnos med nasiljem in socialno pravičnostjo, strukturno nasilje ... Skušala bom analizirati in razjasniti pojem nasilje, prikazati različna stališča v zvezi z nasiljem, vključno z moralnimi in drugimi načeli ter vrednotami, na katerih ta stališča temeljijo. Predstavila bom različne poskuse, kako nevtralno, amoralno definirati nasilje. Takšna nevtralna, amoralna opredelitev nasilja je potrebna, če sploh hočemo govoriti o moralni upravičenosti nasilja. Nasilje namreč ni slabo po definiciji. $\mathrm{V}$ nasprotnem primeru bi bilo nasilje normativni 
koncept: takoj, ko bi nekaj označili kot nasilje, bi to že zadostovalo, da to dejanje obsodimo. Moramo namreč razlikovati med tem, ali je nekaj že po definiciji slabo ali je prima facie slabo. Dejanja nasilja niso slaba po definiciji, ampak so prima facie slaba, zato potrebujejo opravičilo oz. zagovor (Bufacchi, 2007: 6). Na primer: v primeru samoobrambe je nasilje legalno in moralno sprejemljivo; če terorizem razumemo kot naključno ubijanje nedolžnih ljudi, je moralno nesprejemljivo.

Začela bom z lingvistično analizo pojma nasilja, iz katere izhajata tudi dva glavna pristopa $\mathrm{k}$ razumevanju in definiranju nasilja: ožji pristop, ki nasilje enači z uporabo sile, in širši pristop, ki nasilje opredeli kot kršitev. Nato bom skušala prikazali prednosti in slabosti obeh omenjenih pristopov k nasilju. Sledila bo Bufacchijeva definicija nasilja, ki nasilje opredeli kot kršitev integritete in zavzema vmesni prostor med t.i. ožjim in širšim pojmovanjem nasilja. Na koncu pa bom namenila še nekaj besed moralni upravičenosti nasilja.

\section{Nasilje}

Termin nasilje (ang. violence) izhaja iz latinske besede violentia, ki pomeni silovitost, divjost, nebrzdano in nekontrolirano moč. Ker pa dejanja prekomerne uporabe sile pogosto rezultirajo $\mathrm{v}$ kršitvi zakonov, pravil ali pravic, je nasilje pogosto povezano s prekršitvijo (ang. violation, lat. violare: prekršitev, oz. violo: s silo ravnati s kom, prekršiti, prelomiti).

Od tod izhajata tudi dva glavna pristopa $\mathrm{k}$ razumevanju in definiranju nasilja: ožji, minimalistični pristop, kjer ima pri definiranju nasilja odločujočo vlogo sila oz. moč: nasilje kot (pretirana) uporaba fizične sile z namenom poškodovati osebe ali lastnino, in širši pristop, ki pojmuje nasilje kot kršitev (pravic, pravil...).

Obstajajo tudi poskusi, ki skušajo združiti oba pristopa. ${ }^{5}$ Pri tem pa se pojavijo težave: posledice dejanj pretirane uporabe fizične sile so sicer pogosto tudi neke vrste kršitev (npr. rop, posilstvo), vendar obstajajo tudi primeri, ko se kršitev zgodi brez uporabe fizične sile (npr. žrtev je pred posilstvom omamljena), in primeri, ko pretirana uporaba sile nima za posledico kršitve (npr. sporazumen spolni odnos grobe narave).

Poleg teh dveh glavnih pristopov $\mathrm{k}$ nasilju velja omeniti tudi Levinasovo zelo široko definicijo nasilja, ki vključuje kakršno koli silo ali moč, karakterizira tako naravne pojave, kot tudi oblike človeških interakcij. V delu Težavna svoboda pravi:

Na primer v Slovarju slovenskega knjižnega jezika (1994) je nasilje opredeljeno kot dejaven odnos do koga, značilen po uporabi sile, pritiska, in kot dejanje ali ravnanje, ki ni v skladu z bistvenimi resničnimi značilnostmi, zakonitostmi nečesa. 
Vendar pa nasilje ni samo v biljardni krogli, ko ta zadane drugo, v nevihti, ki uniči letino, v gospodarju, ki slabo ravna s sužnjem, v totalitarni državi, ki ponižuje svoje državljane, v vojaškem osvajanju, ki si podjarmi prebivalce. Nasilno je vsako dejanje, v katerem se obnašamo, kot bi bili sami. Kot da bi bil tam preostanek vesolja samo zato, da sprejme naše dejanje. Torej je nasilno tudi vsako dejanje, ki ga prestajamo, ne da bi v njem v polnosti sodelovali. $V$ tem smislu je nasilna vsa vzročnost: izdelava stvari, zadovoljitev potrebe, želja in celo poznavanje nekega objekta. Tudi boj in vojna sta nasilna, saj v bližnjem iščeta šibkost, ki izdaja njegovo osebo. Zvečine pa je nasilje tudi v poetični pijanosti, v vzhičenosti, v kateri muzi samo ponujamo svoja usta, da skoznje spregovori. Nasilje je v našem strahu in drgetu, ko nas Sakralno iztrga iz nas samih, je v strasti, četudi je ta ljubezen, ki z izdajalsko puščico rani našo srčno stran. (Levinas, 20I2: 8)

Za Levinasa nasilje ni le središčni pojem političnih ali moralnih teorij, Levinas misli nasilje tudi kot metafizično, ontološko, fenomenološko in eshatološko kategorijo. ${ }^{6}$

Preden se lotimo analize obeh pristopov k nasilju, še nekaj besed o t.i. subjektivizmu. V zadnjem času, ugotavlja Bufacchi (Buffacchi: 2007: 30-33), postaja vedno bolj sprejemljiva trditev, da koncept nasilja sam po sebi ne vodi k eni univerzalni večnamenski teoriji. Poudarja se, da je nasilje v različnih kulturah opredeljeno različno, zato ne moremo govoriti o univerzalnem pojmu nasilja, saj je družbeni pomen nasilja določen v kontekstu, v katerem se nasilje zgodi, in z družbenimi dejavniki, ki prevladujejo v določenem družbenem prostoru. Zagovorniki takšnega pojmovanja torej pravijo, da je treba analizo nasilja zasnovati na subjektivnosti in različnih (rivalskih) zahtevah legitimnosti. Takšen subjektivistični pristop odraža filozofsko zaničevanje etike s strani privržencev logičnega pozitivizma, ki pravijo, da etične sodbe niso kognitivne, ampak so čustvene in zato niso nič več kot izrazi »hujskaštva «.

Prekomerni subjektivizem pri razumevanju nasilja lahko resno ogrozi vsako upanje, da bi prišli do univerzalne moralne razumske obsodbe nasilja. Dejanja nasilja, kot so mučenje, posilstvo, smrtna kazen, morajo biti spoznana kot nasilje in obsojena na objektivnih temeljih, čeprav so te prakse v določenih kulturah sprejemljive. Prepoznane morajo biti kot nasilje na univerzalni ravni.

\section{Nasilje kot sila}

Pri mnogih definicijah nasilja igra določujočo vlogo sila. Na primer v Oxford English Dictionary je nasilje opredeljeno kot izvrševanje fizične 
sile z namenom poškodovati osebo ali lastnino. ${ }^{7}$ Mnoge definicije nasilja poudarjajo, da nasilje nujno vsebuje usmerjeno fizično dejanje, ki povzroči škodo ali uničenje. Na primer Honderich pojmuje nasilje kot »uporabo fizične sile, ki stori krivico, poškoduje, oskruni ali uniči ljudi ali stvari« (Honderich, 2002: 9I). Takšno razumevanje nasilja bi lahko označili kot običajno. Tisti, ki zagovarjajo definicijo nasilja s silo, ne trdijo, da sta sila in nasilje sinonima. Vsaka uporaba sile namreč še ni nasilje (npr. če pri reševanju uporabljamo silo) in vsako nasilje ne zahteva uporabe sile (npr. umor s strupom). Nekateri poudarjajo, da šele, ko postane sila destruktivna in škodljiva, se obrne $\mathrm{v}$ nasilje: $\mathrm{z}$ dinamitom lahko razstrelimo ljudi ali pa skale. ${ }^{8}$ Poleg destruktivne narave sile se pogosto poudarja, da mora biti dejanje prekomerne uporabe sile tudi namerno (s strani povzročitelja) in nezaželeno (s strani žrtve). ${ }^{9}$ Nezaželenost pri dejanju nasilja je pomembna zato, da razlikujemo nasilje, npr. mučenje, od drugih primerov intencionalne, prekomerne uporabe sile, ki ne predstavljajo nasilja, npr. kirurški poseg (Bobbio et al.,1990: 122I). Ne moremo pa reči, da je nasilje vedno nezaželeno; s tem bi iz področja nasilja izključili primere strukturnega nasilja. Zaželenosti oz. nezaželenosti tudi ne smemo enačiti s privolitvijo oziroma neprivolitvijo. Privolitev je šibak indikator tega, kaj je zaželeno oziroma nezaželeno. Samo dejstvo, da nekdo privoli v neko dejanje, še ne pomeni, da nimamo opravka z nasiljem. Tudi pri sporazumnih dejanjih seksualnih perverznosti gre za nasilje, za nasilje, ki pa je upravičeno na etičnih osnovah. Definicije nasilja namreč ne smemo mešati z opravičevanjem nasilja - zaželene nasilne kršitve so dejanja nasilja. Privolitev lahko odloča o legitimnosti dejanja, ne pa o njegovi naravi.

Pri definiranju nasilja s prekomerno uporabo sile je treba opozoriti še na kvalitativno razliko med silo in nasiljem. R.P. Wolff silo definira kot »zmožnost narediti spremembo v svetu s fizičnim naporom « (Wolff, 1969: 604). Hannah Arendt pa pravi: »Sila (force), ki jo v vsakdanji govorici pogosto rabimo kot sinonim za nasilje, še posebej, če nasilje služi kot sredstvo prisile, bi morala biti v terminološkem jeziku rezervirana za ,sile narave' (forces of nature) ali za ,silo razmer' (la force des choses), to pomeni, za označitev določenih kvantov energije, ki jo sprožijo fizična ali družbena gibanja.« (Arendt, 2013: 39) Torej, če sledimo Arendtovi, v naravi nimamo opravka z nasiljem: če na primer udari strela, je to izven dometa neposrednih človeških moči, na to človek ne more vplivati, v tem primeru gre

\footnotetext{
7 Gl. Shorter Oxford English Dictionary on Historical Principels, Sixth Edition, Volume 2, N-Z, 2009: 3535.

8 Gl. npr. Dewey, 1980: 246.

9 Prim. Gert, 1969: 616, in Keane, 1996: 66-67.
} 
za sile narave. Ko pa imamo opravka s človekom, ki uporablja svojo naravno dano silo proti drugemu človeku, govorimo o nasilju. ${ }^{\text {Io }}$

Ti definiciji sile kažeta na dve kvalitativni razliki med silo in nasiljem. Prvič: sila je podobno kot moč dispozicijski pojem v tem smislu, da referira na zmožnost oz. potencialnost. Nasilje pa referira na dejanje samo. Nasilje je nekaj, kar je vedno že storjeno in je narejeno nekomu ali nečemu. Drugič: nasilje je vrednostni pojem, sila pa ni. Prav ta moralna nevtralnost sile odvrača Hanno Arendt od tega, da bi jo vključila v opredelitev nasilja.

Razlika med silo in nasiljem daje slutiti, da je definicija nasilja, opredeljena zgolj s prekomerno uporabo fizične sile, preveč omejena in izključujoča. Po eni strani je jasno, da sta to dva različna pojma, po drugi strani pa, da en lahko vključuje tudi drugega. Poleg tega ta definicija nasilja ne zaobjame nekaterih pomembnih vrst oziroma vidikov nasilja, kot so:

- $\quad$ psihološka dimenzija nasilja, ki je včasih hujša od fizične (npr. življenje pod stalnimi grožnjami pri družinskem nasilju, preživele žrtve genocida ali mučenja pogosto omenjajo, da je bilo psihološko nasilje hujše od fizičnega);

- $\quad$ strukturno nasilje ${ }^{\text {II }}$ - t.j. nasilje, ki ga povzročajo družbene in ekonomske nepravičnosti, kar pomeni zmanjšano stopnjo realizacije človekovih potreb in kvalitete življenja pri določenih skupinah ljudi. Razlika med strukturnim nasiljem in ostalimi vrstami nasilja se kaže v tem, da so razmerja med nosilci moči pri strukturnem nasilju precej zabrisana, obstajajo v različnih oblikah, vtkanih v obstoječo družbeno strukturo, v socialne, politične in ekonomske sisteme, ${ }^{12}$ ki vladajo družbam, državam in v končni fazi tudi svetu. Osnovna karakteristika strukturnega nasilja je torej ta, da ne moremo natančno določiti povzročitelja nasilja oziroma katerekoli osebe, ki je neposredno odgovorna za nasilje, kot to lahko storimo pri neposrednem nasilju. In če je neposredno nasilje dejanje, ki ga stori storilec, ki ga lahko identificiramo, bi za strukturno nasilje lahko rekli, da je proces. Poleg tega gre pri strukturnem nasilju za subtilnejšo, po navadi skrito, obliko nasilja. Strukturno nasilje je nasilje, vgrajeno v sistem, iz fascinirajoče vabe neposrednega subjektivnega nasilja, katerega agent je docela določljiv, in se osredotočiti na obrise ozadja, ki generira te izbruhe; takšen korak nazaj nam omogoči identifikacijo tistega nasilja, ki ohranja pri življenju poskuse boja proti nasilju in ki promovira strpnost. /... / Subjektivno nasilje je zgolj najvidnejši vrh trikotnika, ki vključuje simbolno nasilje - nasilje, ki je utelešeno v jeziku, ki tvori našo , hišo biti', kot se je izrazil Heidegger - in sistemsko nasilje - pogosto katastrofične posledice, gladkega delovanja naših ekonomskih in političnih sistemov.« 
kaže se kot neenaka razporeditev moči in s tem posledično kot neenake življenjske možnosti. Skratka, vse nepravične situacije, ki postavljajo ljudi v stanja alienacije, izključitve, pomanjkanja ali zatiranja, so primeri strukturnega nasilja.

- nasilje z opustitvijo; najbolj ekstremni primeri zanemarjanja ali opustitve so tudi oblika nasilja, četudi zanemarjanje ali opustitev pomeni, da nečesa nismo storili. Zanemarjanje ima lahko različne oblike - od prepustitve, zapuščenosti do spregledanja ali ignoriranja določenih situacij. Na primer: deklica iz Ruande je bila priča genocidu, pokolu njenih sovaščanov, bila je pretepena in posiljena. Ta deklica je žrtev dveh ločenih dejanj nasilja: direktnega dejanja agresorja in posiljevalca ter indirektnega dejanja opustitve mednarodne skupnosti, ki ni intervenirala, da bi ta genocid preprečila. Ta primer jasno kaže, da do nasilja lahko pride $\mathrm{z}$ nekim usmerjenim delovanjem in tudi $\mathrm{z}$ nedelovanjem - z opustitvijo. Opustitev je prav tako dejanje nasilja. ${ }^{13}$

\section{Nasilje kot (pre)kršitev}

Ta pristop nasilje definira kot kršitev, prekoračitev nekaterih mej ali pravil. Problem oziroma nesoglasje zagovornikov te opredelitve nasilja se kaže v vprašanju, kaj je tisto, kar je kršeno pri dejanju nasilja. Najpogostejši odgovor je: kršenje pravic. Ta odgovor pa je zavajajoč. Kot ugotavlja Bufacchi (Bufacchi, 2007: I4), obstajajo vsaj trije različni sklopi pravic, ki so z nasiljem lahko kršeni:

- $\quad$ kršitev osebnih pravic, ki se nanašajo na telo ali dostojanstvo osebe;

- kršitev pravice do nas samih v najširšem pomenu besede;

- kršitev človekovih pravic v najširšem smislu, tako da obsegajo tudi vse ovire, ki onemogočajo zadovoljitev osnovnih potreb. Na primer, ljudje, ki stradajo zaradi socialnih ali političnih vzrokov, so žrtve socialnega nasilja.

Če definiramo nasilje kot kršitev pravic, se pri tem pojavita dva problema: prvič, lahko se zgodi nasilje brez kršitve pravic, in drugič, poleg kršitve naših osnovnih pravic, kot je pravica do življenja, varnosti, svobode, lahko nasilje vključuje tudi kršitev drugih socialno-ekonomskih pravic. Skratka, širša, kot je določitev človekovih pravic, bolj vseprisotno in neizogibno postaja nasilje. To nas lahko vodi v skrajnost, ko lahko za skoraj vsako dejanje rečemo, da krši pravico nekoga. Tako najdemo nasilje povsod $-s$ tem pa postane brez pomena. Drugače: takšna razširitev koncept nasilja potopi v nekakšno nerazločeno gmoto, tako da izgubi specifične

I3 Gl. Bufacchi, 2007: 48-64. 
poteze in ni več mogoče določiti, kaj nasilje sploh je. V izogib tem težavam nekateri avtorji predlagajo, da takrat, ko govorimo o nasilju, vendarle uporabljamo »staromodne konotacije « oz. bolj omejene definicije nasilja, v katerih ima nasilje podoben pomen kot v običajnem jeziku, namreč kot uporaba fizične ali psihološke sile z namenom prizadeti ali poškodovati osebe ali lastnino. ${ }^{\text {I4 }}$

\section{Nasilje kot kršitev integritete}

Temeljno nesoglasje med zagovorniki pojmovanja nasilja kot pretirane uporabe sile in zagovorniki pojmovanja nasilja s kršitvijo pravic se kaže v vprašanju, s katerega stališča naj bo nasilje definirano: $s$ stališča povzročitelja/storilca (sila) ali žrtve (kršitev). Če se pri definiranju nasilja postavimo na stran osebe, ki nasilje izvaja, tvegamo, da zgrešimo pravo naravo nasilja in se osredotočamo na tiste postopke legitimacije, ki upravičujejo sredstva s cilji. Bufacchi predlaga tretji pristop: definicijo nasilja s stališča nepristranskega opazovalca (Bufacchi, 2007: 33-38). Pravi, da je nasilje po svojem bistvu družbeno dejanje,v katerem vlada trilateralno razmerje med storilcem nasilja, žrtvijo in hipotetično nepristranskim opazovalcem. In prav stališče nepristranskega opazovalca omogoča definicijo nasilja na nesubjektivistični osnovi.

Da bi šli onstran subjektivizma, moramo pristopiti k nasilju s stališča socialne dinamike, ki omogoča bolj objektivno definicijo pojma nasilja. Nasilje ni nekaj, kar se zgodi, je nekaj, kar ljudje počnejo. Natančneje: nasilje ni nekaj, kar ljudje na splošno počnejo, ampak je vedno storjeno nekomu in/ali nečemu. Nasilje se torej vedno dogaja v socialnem oz. družbenem kontekstu. ${ }^{15}$ Predstavlja nek odnos. Na najbolj osnovni ravni gre za bilateralni odnos med storilcem nasilnega dejanja in žrtvijo. Na ta način sicer lahko razložimo veliko dejanj nasilja, vendar ne vseh, saj ta odnos ne zaobseže kompleksnosti nasilja. Problem bilateralnega odnosa je tudi subjektivnost. To ne pomeni, da subjektivnost sama po sebi predstavlja problem. Nasprotno, ni dvoma o tem, da je v dinamiki nasilja najpomembnejši glas žrtve (npr. priče žrtev holokavsta). Ne more pa biti samo poročilo žrtve ali storilca odločilno. Tu nastopi vloga opazovalca, ki lahko določi perspektivo, iz katere poročila žrtve in storilca kritično presojamo. Poleg tega nas lahko opazovalec opozori na nasilje tudi, če ne slišimo glasu žrtve; to se zgodi v primeru, ko se storilec in/ali žrtev ne zavedata

I4 Gl.npr.: Coady, 2003: 15, in Keane, 1996: 66.

I5 Trditev, da se nasilje vedno dogaja v socialnem oz. družbenem kontekstu, na prvi pogled zanemarja nasilje nad samim sabo. Vendar pa je tudi nasilje nad samim sabo vpeto v družbeni kontekst, je del procesa, $v$ katerem se oseba umika iz »normalnega « sveta v svet psihoz, duševnih bolezni. 
nasilja, ko nasilje ni nezaželeno, pri strukturnem nasilju. Ustreznejši pristop k tej problematiki torej predstavlja trojni odnos med storilcem, žrtvijo in opazovalcem. Opazovalec reprezentira hipotetično perspektivo in deluje iz idealne pozicije, ki mu omogoča, da pride do bolj objektivne sodbe kot žrtev ali storilec. Njegov pogled je pogled od nikogar, je nepristranski pogled, ki omogoča, da se določene prakse prepoznajo kot dejanja nasilja tudi, če niso kot nasilje okarakterizirane s subjektivističnega stališča storilca ali žrtve nasilja. Skratka, opazovalec lahko poda bolj objektivno sodbo kot storilec ali žrtev.

Problem, ki se pojavi na tej točki, pa je, kaj naj opazovalec opazuje, ko sodi oz. da sploh lahko sodi o tem, ali je neko dejanje tudi dejanje nasilja. Splošno sprejeto mnenje je, da sta poškodovanje in povzročanje trpljenja bistveni določili nasilja. $S$ tem soglašajo tako zagovorniki ideje nasilja kot uporabe prekomerne sile kot tisti, ki razumejo nasilje kot kršitev pravic. Razhajanja se potem pokažejo pri vprašanjih, kot so, kako poškodba ali trpljenje nastaneta, ali sta rezultat prekomerne uporabe sile ali kršitve pravic. Dejstvo pa je, da oba pristopa k nasilju izhajata iz te točke.

Tudi če sprejmemo stališče, da sta poškodovanje in povzročanje trpljenja izhodiščni točki, iz katerih lahko izpeljemo definicijo nasilja, pa $s$ tem problema še nismo rešili. Poleg tega, da pride do težav že pri sami opredelitvi teh dveh terminov, pa sta lahko poškodovanje in trpljenje samo sekundarna simptoma, ki imata globlji vzrok. Drugače: poškodovanje in trpljenje sta termina, $s$ katerima opišemo posledice nasilja, ta dva termina pa ne konstituirata dejanja nasilja samega po sebi. Tako smo prišli do točke, kjer Bufacchi vpelje svojo definicijo nasilja - nasilje pojmuje kot kršitev integritete (Bufacchi, 2007: 40). Poškodovanje in povzročanje trpljenja sta samo zunanja znaka, ki imata svoj vzrok v kršitvi integritete.

Integriteto lahko razumemo na dva načina, kot moralni ali kot amoralni koncept. Moralno konotacijo integritete še najbližje zaobsežemo $s$ pojmom poštenost. $S$ tem je integriteta postavljena $\mathrm{v}$ moralno filozofijo, $\mathrm{v}$ sklop spoštovanja etičnih vrlin. Nanaša se na kvaliteto moralnega značaja osebe, ki jo opredeljuje nepokvarljivost ali celo nedolžnost (čistost). Če pa integriteti odstranimo moralni pomen, potem jo lahko opredelimo $s$ pojmom enotnosti, celosti oz. celotnosti ali nedotakljivosti. Referira na nekaj, kar ni razbito, kar ni izgubilo svoje prvotne oblike. V tem drugem smislu Bufacchi uporablja pojem integritete, ko skuša opredeliti nasilje. Nasilje, pravi, je v osnovi kršitev integritete v smislu, da poškoduje ali uniči prej obstoječo enotnost. Ko neka oseba postane žrtev nasilja, je poseženo v njeno integriteto - v procesu kršitve je reducirana na manjvredno bitje v fizičnem in/ali psihološkem smislu. Sama izkušnja krivice, trpljenja ali poškodovanja je samo posledica ali simptom tega, da je bila kršena 
integriteta. Ne smemo namreč zamenjevati simptoma z boleznijo. Nasilje torej Bufacchi definira tako: $\gg$ Dejanje nasilja se zgodi, ko je integriteta ali enotnost subjekta (osebe ali živali) ali objekta (lastnine) namerno ali nenamerno, kot rezultat delovanja ali opustitve, kršena. Kršitev se lahko dogodi na fizični ali psihološki ravni, s fizičnimi ali psihološkimi sredstvi. Kršitev integritete se po navadi kaže v tem, da je subjekt poškodovan ali da mu je bila storjena krivica ali da je objekt uničen ali poškodovan.« (Ibid.)

Lahko bi rekli, da pojmovanje nasilja kot kršitve integritete zavzame vmesni prostor med ožjo določitvijo nasilja kot prekomerne uporabe sile in širšo definicijo nasilja kot kršitve pravic. Prvi pristop je bil, kot smo videli, premalo vključujoč, drugi morda preveč. $V$ definicijo nasilja kot kršitve integritete lahko vključimo več primerov nasilja kot v zgoraj omenjeno ožjo definicijo, kjer je nasilje razumljeno zgolj kot intencionalno dejanje prekomerne uporabe sile, obenem pa ne vključuje kršitve kakršnih koli pravic kot prej omenjeni širši pristop $\mathrm{k}$ nasilju. Kršitev je omejena na integriteto in kršitev integritete kdaj tudi sovpada s kršitvijo pravic, ni pa že vsaka kršitev pravic tudi kršitev integritete. Kršitev integritete se lahko kaže tudi v dejanjih prekomerne uporabe fizične sile (npr. udarec v glavo poškoduje fizično integriteto osebe), vendar se kršitev integritete lahko zgodi tudi brez prekomerne uporabe sile.

Skratka: bistvo te definicije je $\mathrm{v}$ tem, da je nasilje $\mathrm{v}$ osnovi kršitev integritete subjekta ali objekta, ki trpi nasilje, in to v smislu, da nasilje žrtvi nekaj vzame in tako razbije prej obstoječo psihološko in/ali fizično enotnost - enotnost, ki je obstajala, preden se je nasilje zgodilo.

\section{Moralna upravičenost nasilja}

Ali lahko nasilje, čeprav je slabo, uporabimo za namen, ki je dober, oziroma, ali je lahko nasilje moralno upravičeno? Nekateri menijo (npr. Gandhi, Martin Luther King), da nasilje ne more biti nikoli in pod nobenimi pogoji upravičeno, niti za doseganje pravičnosti. Vedno obstaja alternativa nasilju.

Vendar pa, čeprav ne more nihče zanikati tega, da je nasilje slabo in nekaj, kar je napačno in krivično, nekateri teoretiki trdijo, da obstajajo primeri, ko je mogoče nasilje vsaj v principu upravičiti. Na primer, če živimo v skrajno nepravični družbi, če so zakoni v tej družbi nepravični, potem je uporaba nasilja za odpravo nepravičnosti ne samo možnost, ampak tudi dolžnost. Na slednje se navezuje vsa političnopravna teorija o $\gg$ uboju tirana . V človeški zgodovini obstaja več primerov, ko je bila v določeni družbi nepravičnost vsiljena z nasiljem. Zato je treba dovoliti uporabo nasilja tudi za odpravo nepravičnosti. 
Pozitivni odgovor na teoretično vprašanje o moralni upravičenosti nasilja odpira dve novi vprašanji: Kaj dobrega lahko sploh pride iz nečesa, kar je slabo? In, če predpostavimo, da je nasilje lahko moralno upravičeno: Katere vrste nasilja so upravičene in v kolikšni meri? Buffachi navaja dva argumenta, argument identitete in konsekvencialstični argument (Bufacchi, 2007: 168).

\section{Argument identitete}

En način, $s$ katerim lahko zagovarjamo nasilje, je ta, da predpostavimo, da nasilje ni samo slabo, da je tako dobro kot tudi slabo. Ko hočemo torej nasilje upravičiti, ga upravičujemo z njegove dobre strani. Vendar pa, za koga je lahko nasilje dobro. Verjetno ne za žrtve nasilja. Nasilje je torej lahko dobro le za nosilce - povzročitelje nasilja. V kakšnem smislu? Tako, da ima povzročitelj nasilja potem o sebi dobro mnenje. Sliši se paradoksalno: Kako lahko nekdo preko nasilja, preko kršitve integritete neke osebe, dobi o sebi dobro mnenje? Odgovor najdemo $v$ t.i. argumentu identitete:

Nasilje je dobro, če je, skozi dejanje nasilja, povzročitelj zmožen ponovno vzpostaviti svojo lastno identiteto, če je zmožen vzpostaviti se kot oseba z neko moralno vrednostjo, ki si zasluži spoštovanje drugih. (Ibid.: 170)

Najbolj znano navedbo argumenta identitete najdemo $\mathrm{v}$ poročilu Frantza Fanona o nasilju proti kolonialni moči. ${ }^{16}$ Bistvo njegovega argumenta je prepričanje, da kolonizacija ustvari posebno vrsto nasilja, ki se ga lahko premaga samo z nasprotnim nasiljem. Nasilje kolonizacije je posebno v tem smislu, da je tako fizično kot tudi psihološko. Fizična komponenta je očitna: jemanje s silo tistega, kar po pravici pripada koloniziranim. Poleg tega fizičnega nasilja kolonizacija povzroča tudi psihološko nasilje, na katerega se osredotoča Fanon, ki pravi, da kolonizacija predstavlja med kolonizatorji in koloniziranimi odnos moči. Kolonizatorji so na superiorni poziciji, kolonizirani pa se čutijo inferiorne, podrejene. Kolonizacija je ponižujoča na zelo osebni ravni, saj spodkopava občutek identitete in samospoštovanja tistih, ki so kolonizirani. Zaradi tega nasilje kolonizacije kliče k nasilju dekolonizacije, dekolonizacija se zavzema zato, da bi se obstoječe razmerje moči obrnilo. Skozi ta proces dekolonizacije torej kolonizirani lahko zopet vzpostavijo, utrdijo svojo identiteto in dobijo nazaj samospoštovanje. Ta Fanonova teza je postala zelo vplivna v Franciji in državah s kolonialno preteklostjo. Obtožili so ga celo, da je pomembno vplival na teroristična gibanja. Vendar pa je verjetno le kot politični realist

16 Povzeto po: Buffachi 2007: 170-171. 
opazoval, da je nasilje, ki je prisotno pri dekolonizaciji, odgovor na nasilje kolonizacije.

Argument identitete torej predstavlja mnenje, da je nasilje lahko (deloma) dobro, ker lahko preko nasilja tisti, ki so bili z nasiljem ponižani, zopet vzpostavijo oziroma obnovijo svojo identiteto.

Ta argument do neke mere drži. Vsekakor obstajajo primeri, ko so dejanja kolektivnega nasilja dvignila v upor zatirane, da so se postavili zoper tirane (primer: boj proti apartheidu v Južni Afriki). Nasilje je imelo pomembno vlogo tudi pri vzpostavitvi etničnih entitet. Vendar pa nas takšni primeri ne smejo zapeljati v nekakšno poveličevanje nasilja. Argument identitete ima tudi svoje šibke točke. Obstaja namreč tanka meja med uporabo tega argumenta za upravičevanje nasilja in uporabo tega argumenta kot opravičila za nasilje. Lahko bi rekli, da argument identitete sam po sebi na prelahek način upraviči nasilje.

\section{Konsekvencialistični argument ${ }^{17}$}

Drugi argument, s katerim nekateri upravičujejo nasilje, je konsekvencialistični argument. Konsekvecialistična etika presoja človeško delovanje izključno glede na njegove posledice. Če prevladujejo dobre posledice, je dejanje pravilno, dobro, če prevladujejo slabe, je dejanje napačno, slabo. Nič ni torej pravilno ali napačno oz. dobro ali slabo samo po sebi, temveč le glede na posledice. $\mathrm{O}$ tem, ali so posledice dobre ali slabe, se odloča glede na to, kako vplivajo na ljudi, ki jih zadevajo. To pomeni, da tudi nasilje ni nepravilno oziroma slabo samo po sebi, ampak le, če prevladajo slabe posledice. Tisti, ki razmišljajo o nasilju s konsekvencialističnega stališča, se med seboj razlikujejo v oceni moralnosti nasilja: njihova presoja nasilja je odvisna od tega, kako vidijo dobro, za katerega bi si morali prizadevati, in od njihove ocene uporabnosti nasilja kot sredstva za doseganje tega dobrega.

Konsekvencialistični argument bi se torej lahko glasil: Nasilje je upravičeno takrat, ko je nujno zlo, ko je neizogibno sredstvo za preprečevanje še hujšega zla in/ali za napredovanje proti večjemu dobremu.

Ta konsekvencialistični argument predstavlja najbolj običajno logiko upravičevanja uporabe nasilja. Vendar pa te konsekvecialistične sodbe ne smejo biti osnovane na nekakšni obliki filozofskega utilitarizma. Ne smejo se zanašati samo na eno merilo koristnosti, na primer samo na trpljenje ali srečo. Konsekvencialistična utemeljevanja naj bi uporabljala tudi druge kazalce, kot so svoboda, enakost, pravice, ki se jih ne da reducirati zgolj na korist.

I7 Konsekvencializem izhaja iz utilitarizma, ki trdi, da je moralno pravilno dejanje ali politika tisto ali tista, ki proizvede največjo srečo članov družbe. Gl. npr. Mill, 2003. 
Izrazito konsekvencialistični pristop k nasilju oz., bolje rečeno, terorizmu je zagovarjal tudi Lev Trocki. V knjigi Terorizem in komuni$z e m$ odgovarja na obsodbo rdečega terorja s strani Karla Kautskega. Tako Kautsky kot Trocki sta bila marksista, zavzemala sta se za neoviran razvoj človekove narave, ki da je možen le v družbi, ki ni več zaznamovana $\mathrm{z}$ delitvijo na razrede in $\mathrm{z}$ razrednim bojem. Razhajala pa sta se pri vprašanju, ali je za odpravo kapitalistične družbe in njeno zamenjavo $s$ socialistično družbo nujna uporaba vsesplošnega nasilja, še posebej terorizma. Kautsky je menil, da je mogoče v 20. stoletju revolucionarno preobrazbo družbe doseči tudi brez vsiljevanja »vladavine terorja «, brez partijske diktature $\mathrm{z}$ revolucionarnimi sodišči in izrednimi komisijami, ki so imela praktično neomejena pooblastila. Sredstva, ki so jih boljševiki uporabljali za dosego svojih ciljev, so te cilje povsem razvrednotila in »rdeči teror « je bil po mnenju Kautskega moralna katastrofa. Trocki v nasprotju s Kautskim meni, da se nasilju in terorizmu ni mogoče izogniti. Pravi, da čeprav je cilj revolucije, da nas popelje onkraj razredne družbe, je revolucija še vedno produkt te družbe, zato tudi kaže enake slabosti in omejitve: »Da bi osvobodili posameznika, moramo uničiti družbeni red, ki ga tlači. Ta problem pa lahko rešita le kri in jeklo.« (Trocki 2005: 72) Vrsta in stopnja nasilja nista vprašanji moralnih načel, temveč koristi (ibid.: 70). Na obtožbo, da se $\mathrm{z}$ uporabo terorizma boljševiki zatekajo k enakim metodam kot sile starega režima in zato niso nič boljši, Trocki odgovori: Enaka sredstva so lahko pravilna ali nepravilna glede na to, kateremu cilju služijo - teror carizma je usmerjen proti proletariatu, teror boljševikov pa proti tistim, ki skušajo obnoviti kapitalizem, torej »rdeči teror je pravilen«, »beli teror je napačen « (ibid.).

Enako kot argument identitete ima tudi konsekvecialistični argument šibke točke. Ta argument temelji namreč na naslednji predpostavki: Če se dogodi A, potem se povečajo možnosti, da se bo zgodil tudi B. Vendar pa to ne pomeni, da se bo B tudi nujno zgodil, s tem, ko A poveča možnosti za B.

Drugi pomislek glede konsekvencialističnega argumenta lahko opredelimo takole: Kadarkoli je nasilje uporabljeno, tudi upravičeno, obstaja nevarnost, da se sproži t.i. krog nasilja - ko A legitimno uporabi nasilje, da odvrne nelegitimno nasilje $B$-ja, lahko $B$ odgovori še $z$ večjim nasiljem proti A-ju, potem A uporabi še večje nasilje proti B-ju in tako ad infinitum. Izpostaviti je treba še naslednje dejstvo: Ko se zgodi neko nasilje, po navadi to ni izoliran dogodek, nepovezan $\mathrm{z}$ drugimi primeri nasilja, nasprotno, je le del nenehnega procesa, ki povezuje več dejanj nasilja. ${ }^{18}$ 
Če torej upravičimo določeno nasilje, ne upravičimo samo posledic tega dejanja, ampak tudi vse predvidljive možne posledice takšnega dejanja, ki jih to dejanje sproži. Krožna narava nasilja kaže na to, da, ko merimo ceno nasilja, moramo vzeti v zakup tudi proces, $s$ katerim neko dejanje nasilja spodbudi druga dejanja nasilja, ki so lahko še hujša.

Tretji pomislek se kaže v nevarnosti, da konsekvencialističnemu argumentu oziroma načelu koristnosti dovolimo, da razveljavi, revidira naša obstoječa načela, na primer za razločevanje dobrega in zla. Če sprejmemo revizijo teh konceptov, potem smo $s$ tem lahko dopustili, da nobeno dejanje ni imanentno zlo in kot tako prepovedano. Kajti vsa dejanja moramo ocenjevati glede na posledice, in če so te dobre, potem je to dejanje upravičeno, pa čeprav gre za obsodbo nedolžnega, umor ali posilstvo (MacIntyre, 1993: 238-239).

\section{Osnovna načela upravičenja nasilja}

Kako na podlagi vsega do sedaj povedanega sploh lahko še upravičimo nasilje? Pacifisti pravijo, da nasilja ni mogoče nikoli upravičiti, tudi zaradi tega ne, ker, ko je enkrat nasilje dovoljeno, četudi za neko pravično stvar, ne moremo več omejiti njegovega širjenja. Kot primer navajajo drugo svetovno vojno, ki je velikokrat uporabljena kot vzorčni primer upravičenja nasilja, v kateri pa se je zgodilo tudi neupravičeno nasilje. ${ }^{19}$ Njihovo stališče je seveda razumljivo, vendar pa samo na podlagi tega ne moremo obsoditi nasilja nasploh. Tudi če rečemo, da je nasilje mogoče v principu upravičiti, $s$ tem še ne povemo, za katero vrsto nasilja to velja. Tisti, ki zagovarjajo upravičenje nasilja, morajo torej razložiti, katero nasilje je lahko upravičeno. Na primer: lahko rečemo, da t.i. vojna proti terorizmu, ki se je začela po dogodkih ir. septembra 200I, lahko upraviči nekatero nasilje proti teroristom, morda celo ubijanje teroristov, ne more pa upravičiti bombardiranja nedolžnih ljudi, posiljevanja vojnih ujetnikov, mučenja... Postaviti je torej treba neka osnovna načela, principe, na temelju katerih bomo lahko govorili o upravičenju nasilja.

Bufacchi za izhodišče postavi temeljni princip, ki pravi, da morata biti življenje in dostojanstvo vseh oseb ves čas spoštovana (2007: 176-184).

ljih. Velikokrat se kaže povezava med otrokom, ki je žrtev ali priča nasilja v družini, in njegovo udeležbo v vrstniškem nasilju v šoli. Poleg tega obstaja povečano tveganje, da bo ta otrok tudi, ko bo odrasel, izvrševal kazniva dejanja in da bo v družini, ki si jo bo sam ustvaril, prisotno nasilje.

19 Na primer: vojaki Rdeče armade so v dvotedenski bitki za Berlin posilili okoli 130.000 žensk, I0.000 jih je naredilo samomor; problematična so tudi zavezniška bombardiranja nemških mest. O tem glej več npr.v Garret (2005) in Lackey (2005). 
Sledijo mu še štirje principi, ki jih zasledimo v literaturi o »pravični vojni $\ll^{20}$ in ki bolj natančno določajo temeljni princip.

I. Princip samoobrambe: nasilje je dopustno samo kot odgovor na nasilje z namenom, da se odbije napad napadalca. Ta princip je sprejet tudi $v$ mednarodnem pravu. V kazenskem pravu gre za institut silobrana. Kriteriji za silobran so trije: sočasnost napada in obrambe, sorazmernost sredstev in neizzvanost napada. Princip samoobrambe dovoljuje nasilje, da se odbije nasilje, kjer se je napad že zgodil ali pa je neizogiben, ne pa, če je zgolj verjeten.

2. Princip razumnega uspeha (reasonable success): nasilje se lahko uporabi samo, kadar obstaja razumna možnost za uspeh. Kot uspeh je mišljen konec nasilja ali odstranitev izvorne grožnje z nasiljem, ne pa npr. pridobitev neke strateške prednosti (v vojni). Pri tem principu je poudarjeno tudi to, da je treba varovati človeška življenja, tudi med vojno.

3. Princip sorazmernosti: uporaba nasilja mora biti vedno sorazmerna z nasiljem, ki mu stoji nasproti. Sorazmernosti ne smemo zamenjevati z recipročnostjo. To bi pomenilo, da lahko uporabimo proti napadalcu isto vrsto nasilja, kot ga on proti nam, na primer: upravičeno bi bilo posiliti posiljevalca ali mučiti mučitelja, kar pa seveda ni prav.

4. Princip zadnje možnosti: nasilje je lahko moralno upravičeno samo, če so bile prej že izčrpane vse nenasilne, miroljubne možnosti. Čeprav je zelo težko določiti, kaj so vse možnosti, je ta princip pomemben, saj poudarja, da je nasilje, tudi, če je upravičeno, vedno prima facie slabo.

5. Tem štirim principom bi lahko dodali še petega - princip postopnega napredovanja oz. eskalacije: ko uporabljamo nasilje, moramo začeti z minimalnim nasiljem in ga šele postopoma povečevati. To ne pomeni samo, da moramo začeti z nenasilnimi strategijami - princip zadnje možnosti, ampak tudi znotraj možnih nasilnih strategij moramo izbrati najmanj nasilno; če ta ne zadostuje, nasilje postopoma povečujemo. Primer: politična konfrontacija: prva strategija - dialog, potem nenasilna civilna nepokorščina, sledi ji nasilna

20 O teoriji pravične vojne gl. npr. McMahan, 1993: 384-389, in Coates, 1997. Vendar pa, kot opozarja Harold Müller v delu Building New World Order - Sustainable Policies for the Future, je pojem »pravična vojna kontradiktoren: ker vojna nujno povzroči smrt in trpljenje nedolžnih, kar je nepravično, sama ne more biti pravična, lahko je samo opravičljiva. Podobno razmišlja tudi Nenad Miščević v članku »The Dilemas of Just War and the Institutional Pacifism $\ll$ (https://journal.openedition.org/revus/1273https://journal. openedition.org/revus/I273), ko pravi, da je celo pravična vojna lahko samo minimalno in komajda pravična. 
civilna nepokorščina in šele za njo oborožen konflikt, gverila, vojna, revolucija.

Ali je torej nasilje lahko upravičeno? Lahko bi rekli, da ja: Nasilje je lahko upravičeno, vsaj v teoriji. Natančneje: nasilje je lahko upravičeno, če na nasilje gledamo s stališča osebe, ki ga izvaja. Če pa se postavimo na stran žrtve nasilja, je slika drugačna. $S$ tega stališča vidimo nasilje kot tisto, kar osebo spremeni v stvar, v sredstvo, ki se ga lahko poljubno uporabi. To pa je v nasprotju s Kantovim drugim imperativom: »Deluj tako, da boš človeštvo tako v tvoji osebi kakor v osebi vsakogar drugega vselej uporabljal hkrati kot smoter, nikoli/zgolj kot sredstvo.« (Kant 2005: 45) Za razliko od stvari, ki so zgolj instrumentalne - sredstva, ki jih lahko »ta ali ona volja poljubno uporabi« (ibid.: 44), ljudje eksistirajo kot smoter na sebi. In kdor krši to načelo, kdor uporablja druge ljudi kot sredstvo, nad njimi izvaja nasilje.

\section{Zaključek}

Problematika nasilja je zelo kompleksna. Teoretična večplastnost in raznovrstnost vprašanj ter konceptov o sami naravi nasilja potrjujeta, da so problemi in izzivi, s katerimi smo soočeni pri obravnavanju nasilja, vse prej kot enostavni, jasni in enoznačni. To po eni strani pomeni, da je treba nasilje konceptualizirati na način, ki je adekvaten in dojemljiv za čas, v katerem živimo, da moramo identificirati različne oblike nasilja, ki se v sodobnem svetu pojavljajo. Po drugi strani pa kompleksnost in nejasnost omogočata, da se vzpostavijo vrzeli, ki dovoljujejo storilcem nasilnih dejanj, da najdejo širok spekter upravičevanj nasilja, ki lahko postanejo tudi splošno sprejeta. Prvi korak k reševanju te problematike vsekakor predstavlja razumevanje osnovnih konceptov nasilja in pojmov, ki so $\mathrm{z}$ njim povezani.

\section{Literatura}

Arendt, H. (2013) Nasilje.Ljubljana: Krtina.

Bobbio, N., Matteucci, N., Pasquino, G. (1990) Dizionario di politica, TEA.

Bufacchi, V. (2007) Violence and Social Justice, New York: Palgrave.

Coady, C.A.J.(2003) The Idea of Violence, Journal of Applied Philosophy 3 (I), str. 3-19.

Coates, A. J.(1997) The Ethics of War.Manchester: Manchester University Press.

Derrida, J. (2003) Violence and Metaphysics.V: J. Derrida, Writing and Difference, London and New York: Routlege. 
Dewey, J. (1980) Force, Violence and Law in Force and Coercion. V: J.A. Boydstonur., John Dewey, The Middle Works, I899-1924, Vol. 1o.Carbondale:Southern Illinois Press.

Galtung, J. (1969) Violence, Peace and Peace Research.The Journal of Peace Research 6(3), str. 167-191.

Garrett S. A. (2005) Ustrahovalno bombardiranje nemških mest v II. svetovni vojni. V: I. Primorac ur., Terorizem. Filozofska vprašanja.Ljubljana: Krtina.

Gert, B. (1969) Justifying Violence. The Journal of Philosophy 66(19), str. 616-628.

Girard, R. (2006) Gledam satana, ki kakor blisk pada z neba. Ljubljana: KUD Logos.

Honderich, T. (2002) After the Terror.Edinburgh:Edinburg University Press.

Jalušič, V.(2013). Razumeti nasilje (in oblast). V: H. Arendt,Nasilje, Ljubljana: Krtina.

Kant, I. (2005) Utemeljitev metafizike nravi.Ljubljana: Založba ZRC SAZU.

Keane, J. (1996) Reflections on Violence.London: Verso.

Komel, M. (2012) Diskurz in nasilje.Ljubljana: Analecta.

Lackey, D. (2005) Razvoj sodobne teroristične države: območno bombardiranje in jedrsko ustrahovanje. V: I. Primoracur., Terorizem. Filozofska vprašanja.Ljubljana: Krtina.

Levinas, E. (2012) Težavna svoboda: eseji o Judovstvu.Celje: Celjska Mohorjeva družba.

MacIntyre, A. (1993) Kratka zgodovina etike.Ljubljana: Znanstveno in publicistično središče.

McMahan, J. (1993) War and Peace. V:P. Singerur., A Companion to Ethics, Oxford: Blackwell.

Mill, J. S. (2003) Utilitarizem in O svobodi.Ljubljana: Temeljna dela.

Miščević, N."The Dilemas of Just War and the Institutional Pacifism”. https://journal.openedition.org/revus/1273 (18.06.2018).

Müller, H. (2009). Building New World Order - Sustainable Policies for the Future.Chicago: The University of Chicago Press.

Primorac,I.ur. (2005) Terorizem. Filozofska vprašanja. Ljubljana: Krtina.

Shorter Oxford English Dictionary on Historical Principels Sixth Edition Volume 2 N-Z (2009), Oxford, New York: Oxford University Press.

Singer, P. ur. (1993) A Companion to Ethics.Oxford: Blackwell.

Slovar slovenskega knjižnega jezika (1994). Ljubljana: DZS. 
Sveto pismo Stare in Nove zaveze (2005). Ljubljana: Svetopisemska družba Slovenije.

Trocki, L. (2005) Obramba ,rdečega terorja‘. V: I. Primoracur., Terorizem. Filozofska vprašanja.Ljubljana: Krtina.

Žižek, S. (2007) Nasilje.Ljubljana: Analecta.

Wiesthaler, F. (2005) Latinsko slovenski slovar I-VI, Ljubljana: Kres.

Wolff, R. P. (1969) On violence. The Journal of Philosophy 66(19), str. 6oI-6I6.

DOI: https://www.doi.org/10.32320/158I-6044.30(I-2)29-46 